\author{
Justyna Kowal \\ ORCID: 0000-0002-9367-3209 \\ Uniwersytet Wrocławski
}

\title{
Frankensteinowska hybryda
}

https://doi.org/10.19195/0867-7441.25.30

Recenzja: Rafał Donica, Frankenstein - 100 lat $w$ kinie, wyd. 2 rozszerzone, 2016 (e-book), ss. 352.

Słowa kluczowe: Frankenstein, kultura wizualna, kultura popularna, film, klisze

Keywords: Frankenstein, visual culture, popular culture, film, clichés

Książka autorstwa filmoznawcy i krytyka filmowego Rafała Donicy Frankenstein - 100 lat $w$ kinie - jak sam tytuł wskazuje — jest pewnego rodzaju rocznicowym ${ }^{1}$ podsumowaniem funkcjonowania postaci monstrum Frankensteina na szklanym ekranie. Drugie, wzbogacone i poprawione wydanie popularnonaukowego opracowania, oddane w ręce czytelnika w 2016 roku, znacznie poszerza perspektywę badawczą: autor raczej powinien zrezygnować z obecnego w tytule ,filmu” na rzecz szeroko pojętej „,kultury wizualnej”. Analizie poddano (oprócz filmów pełnometrażowych i krótkometrażowych, animacji, seriali i reklam, których opisy w dalszym ciągu stanowią większość objętości książki) także najnowsze sztuki teatralne, komiksy czy dioramy. Autor sprawnie przeprowadza czytelnika przez ogrom informacji: tytułów, dat, nazwisk aktorów i postaci, jego narracja jest hybrydą stylu uszczypliwego felietonisty i drobiazgowego badacza. Różnorodność opracowania Donicy sprawia, że książka przypomina po trosze obiekt jego badań (do czego autor sam przyznaje się we wstępie):

Przez nagromadzenie informacji ze źródeł maści wszelakiej, faktów i ciekawostek na temat Frankensteina, których dowiadywałem się przez ostatnie lata od filmoznawców i fascynatów postaci Frankensteina, mnogości przywołanych filmów, których nie jestem nawet

1 Jako pierwszy film o postaci Frankensteina i jego monstrum Donica podaje szesnastominutową produkcję z 1910 roku Thomas Edison's Frankenstein w reżyserii J. Searle'a Dawleya. 
w stanie zliczyć, niniejsza książka sama w sobie zaczęła przypominać potwora poskładanego z kawałków różnego pochodzenia ${ }^{2}$.

Obecna na każdym poziomie hybrydyczność (lub raczej kolażowość) w przypadku pracy Donicy nie oznacza niespójności i chaosu, w żadnym stopniu nie odbiera wartości jego wywodowi; pozwala koherentnie i wielowymiarowo spojrzeć na wyjątkową w dziejach popkultury postać Frankensteina.

Ciekawie prezentuje się konstrukcja książki, wskazująca na duży szacunek do tekstu źródłowego; wywód poświęcony kulturze wizualnej poprzedzony jest gruntownym omówieniem samego literackiego pierwowzoru autorstwa Mary Shelley, okoliczności powstania utworu, a nawet dziewiętnastowiecznych teorii medycznych, które mogły być inspiracją. W pierwszej części książki czytelnik odnajdzie także charakterystyki Victora Frankensteina i jego monstrum - autor przywołuje dokładny obraz bohaterów wykreowany przez Shelley, by pokazać, jak interpretacje filmowe dalekie są od oryginału i jak przekształcały się przez ponad sto lat (w tym kontekście najbardziej istotne wydaje się przesunięcie znaczenia, przeniesienie nazwiska naukowca na samo monstrum oraz pojawienie się w filmie $^{3}$ - nieobecnego w literackim źródle - jednego z najsłynniejszych cytatów popkultury, okrzyku „It's alive!”). Donica nie zapomina także o starszej siostrze X Muzy i zwięźle opisuje współczesne Mary Shelley teatralne inscenizacje jej dzieła. Analiza filmowa obejmuje blisko trzysta tytułów uporządkowanych chronologicznie (często z zastosowaniem podziału na dekady lub z uwzględnieniem periodyzacji historii sztuki filmowej) i jakościowo (na przykład rozdział Wokót mitu 1986-1998 r.), dzięki czemu czytelnik otrzymuje pełny przekrój filmowego wizerunku monstrum Frankensteina, od złotej ery Universalu po współczesne superprodukcje Netflixa. Dodatkowo autor wprowadza w spisie treści system oznaczeń, które znacznie ułatwiają lekturę, odróżniając chociażby filmy pełnometrażowe od seriali telewizyjnych. Każdy rozdział wyposażony jest w bogaty materiał ilustracyjny i cytaty filmowe, pełniące niekiedy funkcję mott dalszych rozważań, a także zestaw ciekawostek niełączących się bezpośrednio z głównym wywodem.

Imponujący jest także zakres materiału, jakim zajmuje się Donica; nawet pomijając fakt rozszerzenia zainteresowań do całej sztuki wizualnej, spektrum źródeł związane z samym szklanym ekranem jest niezwykle szerokie. Autor oprócz ambitnych filmów pełnometrażowych, eksponujących warstwę etyczną i psychologiczną historii Frankensteina równorzędnie zajmuje się reklamami środków na ból stawów, w których monstrum tłumaczy, że przez reumatyzm porusza się w charakterystyczny dla siebie sposób.

2 R. Donica, Frankenstein - 100 lat w kinie, 2016, s. 3.

3 Jedna z najsłynniejszych kwestii w dziejach kina „It’s alive!” — która znajduje się na 49. miejscu najsłynniejszych kwestii filmowych, między „Nikt nie jest doskonały” z Pót żartem, pót serio, a „Huston, mamy problem” z Apollo XIII — pojawia się po raz pierwszy w Frankensteinie Jamesa Whale'a z 1931 roku. Zob. R. Donica, op. cit., s. 37. 
Chęć autora do wykorzystania jak najszerszej perspektywy badawczej widać także na dwu innych poziomach: ujęciu gatunków filmowych (Frankenstein i motywy towarzyszące pojawiają się w klasycznym kinie grozy, dramacie, gore, found footage, science-fiction, komediach, animacji poklatkowej, anime, a nawet w westernach czy filmach pornograficznych) oraz uwzględnienia zasięgu terytorialnego. Oprócz wielkich produkcji hollywoodzkich pojawiają się filmy z Japonii, Meksyku, państw europejskich, w tym także przykłady z lokalnej, polskiej filmografii.

Wywód Donicy to także historia aktorstwa i twarzy, które w kulturze masowej zostały przypisane doktorowi i jego potworowi (ze szczególnym uwzględnieniem Petera Cushinga i Borisa Karloffa, którego rysy najbardziej kojarzone są z wizerunkiem monstrum). Nowatorskim elementem narracji autora jest próba ukazania filmowego Frankensteina jako wiecznej kliszy, nieustannie cytowanej, reprodukowanej, parodiowanej, wykorzystywanej w różnych kontekstach i wyposażanej w nowe znaczenia. Na szczególną uwagę zasługuje także wspominany już rozdział Wokót mitu 1986-1998 $r$., poświęcony nie tyle samym postaciom z prozy Shelley, ile wątkom metaartstowskim związanym z wieczorkami grozy i genezą literackiego obrazu, a także powstaniem legendarnego Frankensteina z 1931 roku i postacią Jamesa Whale'a. Autor dostrzega ślady Frankensteina także we wszelkich filmowych narracjach, w których pojawia się motyw boskiej kreacji, powołania do życia zdehumanizowanej istoty i aspekt buntu przeciwko własnemu stwórcy.

Mogłoby się wydawać, że Frankenstein - 100 lat w filmie Rafała Donicy to chaotyczne, korzystające z wielu niespójnych narzędzi teoretycznych wyliczenie wszystkich tekstów kultury wizualnej, w których tytule pojawia się słowo „Frankenstein”. Książka zakończona przenikliwą refleksją na temat kondycji współczesnego kina grozy i mitu Frankensteina w systemie popkultury rzeczywiście jest oryginalną — zarówno pod względem merytorycznym, jak i stylistycznym - hybrydą, mimo to czytelnik ma wrażenie, że każda, nawet najbardziej kuriozalna informacja podana przez autora jest nieprzypadkowa i powiększa wiedzę o opisywanym zjawisku, wypełniając ważną lukę w badaniach. Wszystkie poziomy syntezy w opracowaniu są — jak części ciała potwora Frankensteina wobec siebie komplementarne i składają się na cenne kompendium mitu w ujęciu barthes'owskim; mało kto pamięta o jego literackich korzeniach, za to wszyscy doskonale znają jego kliszowe obrazy, upowszechnione przez kulturę wizualną. Zastosowana przez badacza formuła przejrzyście uporządkowanego, popularnonaukowego leksykonu sprawia, że Frankenstein - 100 lat $w$ kinie jest cennym źródłem informacji zarówno dla amatorów kina grozy, jak i profesjonalnych medioznawców. Dzięki zaprezentowaniu ewolucji wizerunku monstrum opracowanie wydaje się szczególnie cenne dla antropologów kultury — w ujęciu Rafała Donicy najistotniejszy jest proces, towarzyszące mu wybory i drobne przesunięcia znaczeń, które doprowadziły do współczesnego obrazu potwora. Co więcej, 
materiał będący przedmiotem badań autora nieustannie się powiększa, co widać szczególnie w wypadku seriali telewizyjnych — wystarczy wspomnieć, że po publikacji drugiego, rozszerzonego wydania pojawiły się kolejne sezony Frankenstein Chronicles (Frankenstein Chronicles reż. Alex Gabassi, Wielka Brytania 2017) czy Domu grozy (Penny Dreadful, reż. Damon Thomas, Toa Fraser, Paco Cabezas, USA-Wielka Brytania 2017).

\title{
Bibliografia
}

\section{Teksty}

Wollstonecraft Shelley M., Frankenstein, przeł. P. Łopatka, Kraków 2009.

\section{Opracowania}

Barthes R., Mitologie, przeł. K. Kłosiński, Warszawa 2008.

Donica R., Frankenstein - 100 lat w kinie, wyd. 2 rozszerzone, 2016 (e-book).

Stownik literatury popularnej, red. T. Żabski, Wrocław 2006.

\section{A Frankensteinian hybrid}

\author{
Summary
}

The review of Frankenstein - 100 lat w kinie describes a unique form of the book proposed by Rafał Donica, Polish film critic and expert in popular culture. The shape of the book remains the object of its deliberations; fragmentary, heterogeneous narration by Donica reflects an idea of Frankenstein's monster body. Donica builds his narration with quotations, critical essays, historical reconstructions and original illustrative material. The author examines the character of Frankenstein's monster in cinema and visual culture, which — as Donica accounts - brought about the transformation of the monster picture, extremely distant from Shelley's prototype. The heterogeneity of Donica's book manifests itself in several fields; the form of character appearance (from feature films, through animated films, TV series to commercials), temporal (from the beginnings of the cinema to present day) and territorial range - the author makes an attempt to present an objective, non-Europocentric point of view, including examples of Frankenstein's monster appearance in Asia or South America. Donica also proves his sensitivity to sociological mechanisms which guides popular culture; he shows how "faces" of famous actors (like Boris Karloff) affected the monster image. 